\title{
Article \\ Mutations Affecting HVO_1357 or HVO_2248 Cause Hypermotility in Haloferax volcanii, Suggesting Roles in Motility Regulation
}

\author{
Michiyah Collins ${ }^{1}{ }^{(}$, , Simisola Afolayan ${ }^{1}$, Aime B. Igiraneza ${ }^{1}$, Heather Schiller ${ }^{1}{ }^{\circledR}$, Elise Krespan ${ }^{2}$, \\ Daniel P. Beiting ${ }^{2}$, Mike Dyall-Smith ${ }^{3,4}\left(\mathbb{D}\right.$, Friedhelm Pfeiffer ${ }^{4}(\mathbb{D}$ and Mechthild Pohlschroder $1, * \mathbb{C}$
}

check for

updates

Citation: Collins, M.; Afolayan, S.;

Igiraneza, A.B.; Schiller, H.;

Krespan, E.; Beiting, D.P.;

Dyall-Smith, M.; Pfeiffer, F.;

Pohlschroder, M. Mutations Affecting

HVO_1357 or HVO_2248 Cause

Hypermotility in Haloferax volcanii,

Suggesting Roles in Motility

Regulation. Genes 2021, 12, 58.

https://doi.org/10.3390/genes

12010058

Received: 21 November 2020

Accepted: 29 December 2020

Published: 31 December 2020

Publisher's Note: MDPI stays neutral with regard to jurisdictional clai$\mathrm{ms}$ in published maps and institutional affiliations.

Copyright: (C) 2020 by the authors. Licensee MDPI, Basel, Switzerland. This article is an open access article distributed under the terms and conditions of the Creative Commons Attribution (CC BY) license (https:// creativecommons.org/licenses/by/ $4.0 /)$.
1 Department of Biology, School of Arts and Sciences, University of Pennsylvania, Philadelphia, PA 19104, USA; michiyah@sas.upenn.edu (M.C.); cmceearemu@yahoo.co.uk (S.A.); iaime@sas.upenn.edu (A.B.I.); hsrs@sas.upenn.edu (H.S.)

2 Department of Pathobiology, School of Veterinary Medicine, University of Pennsylvania, Philadelphia, PA 19104, USA; ekrespan@vet.upenn.edu (E.K.); beiting@vet.upenn.edu (D.P.B.)

3 Veterinary Biosciences, Faculty of Veterinary and Agricultural Sciences, University of Melbourne, Parkville 3010, Australia; mike.dyallsmith@gmail.com

4 Computational Biology Group, Max-Planck-Institute of Biochemistry, 82152 Martinsried, Germany; fpf@biochem.mpg.de

* Correspondence: pohlschr@sas.upenn.edu; Tel.: +1-215-573-2283

Abstract: Motility regulation plays a key role in prokaryotic responses to environmental stimuli. Here, we used a motility screen and selection to isolate hypermotile Haloferax volcanii mutants from a transposon insertion library. Whole genome sequencing revealed that hypermotile mutants were predominantly affected in two genes that encode HVO_1357 and HVO_2248. Alterations of these genes comprised not only transposon insertions but also secondary genome alterations. HVO_1357 contains a domain that was previously identified in the regulation of bacteriorhodopsin transcription, as well as other domains frequently found in two-component regulatory systems. The genes adjacent to hvo_1357 encode a sensor box histidine kinase and a response regulator, key players of a twocomponent regulatory system. None of the homologues of HVO_2248 have been characterized, nor does it contain any of the assigned InterPro domains. However, in a significant number of Haloferax species, the adjacent gene codes for a chemotaxis receptor/transducer. Our results provide a foundation for characterizing the root causes underlying $H f x$. volcanii hypermotility.

Keywords: Haloferax volcanii; archaea; swimming motility; archaella; chemotaxis; hypermotility selection; transposon mutagenesis; two-component regulatory system; extremophiles

\section{Introduction}

Although best known for species that thrive in extreme environments, archaea are actually ubiquitous, playing vital roles in a variety of ecological processes of global significance, including the carbon and nitrogen cycles [1-3]. The human microbiome also includes archaeal species, although their importance to human health is largely unknown $[4,5]$.

Despite this importance and ubiquity of archaea, our understanding of key aspects of archaeal cell biology, including the regulation of swimming motility, remains superficial so far. Swimming motility allows cells to reach optimal conditions. Cells may swim toward energy sources (e.g., nutrients, light) but may also escape from repellents. Additionally, they may reach surfaces where they can form biofilms but can also quickly disperse from biofilms to reestablish a planktonic state. The swimming speed might depend on the need to escape an unfavorable condition.

Prokaryotic motility is frequently facilitated by a rotating filament, the flagellum in bacteria and the archaellum (archaeal flagellum) in archaea [6-8]. Although functionally equivalent, flagella and archaella are unrelated at the molecular level. While flagellar 
rotation is driven by an ion gradient [9], archaellar rotation is driven by ATP hydrolysis [10]. The archaellum is distantly related to type IV pili, including a similar pathway of N-terminal protein maturation by prepilin/prearchaellin peptidase [11-15]. A protein pair involved in archaella biogenesis (ArlI/ArlJ, previously FlaI/FlaJ) is distantly related to the type IV pili biogenesis proteins (PilB/PilC) [16-18]. ArlI, however, is bifunctional, as it is not only involved in archaellar biogenesis but also is an integral part of the archaellar motor $[19,20]$. The kinetics of the archaellar motor of Halobacterium salinarum have been analyzed in detail [21,22], and its step-wise rotation has been directly observed [23].

Directed prokaryotic motility depends on interaction with a (chemo)tactic system, which detects environmental signals by a set of receptors/transducers (Htr: Halobacterial transducer; also known as MCP, methyl-accepting chemotaxis protein) [24,25]. At the core of the signaling cascade is a two-component signal transduction system consisting of the histidine kinase CheA and the response regulator CheY [26-31]. The docking of the bacterial-type chemotactic system to the archaea-specific archaellar motor involves CheF and ArlCDE, as was recently resolved in the halophilic archaeon Haloferax volcanii [32-34]. Cells of Hfx. volcanii vary in shape depending upon growth conditions and can form pleomorphic disk-like forms as well as uniform rods. The tubulin homolog CetZ1 is required for rod formation and is essential for swimming motility [35]. To assist genetic analysis, a Hfx. volcanii transposon insertion library (Tn-library) has been constructed [36] that contains $>4100$ randomly introduced mutants in a genome with ca. 4000 proteincoding genes. The utility of this library in investigating motility has been previously demonstrated by the isolation of non-motile mutants, which revealed transposon insertions (Tn-insertions) between cheW and cheB as well as in pibD, pilB1, and genes not previously suggested to be involved in swimming motility [37,38].

Some archaeal mutant strains were also reported to be hypermotile, providing some additional molecular insights into the archaella biosynthesis, function, and regulation [19,39-42]. To obtain more insight into the phenomenon of hypermotility, we applied several screens to obtain hypermotile $H f x$. volcanii isolates with a Tn-insertion. A large set of isolates was subjected to whole-genome sequencing to identify transposon insertion locations along with single nucleotide polymorphisms (SNPs), deletions, and other secondary genomic variations. Two genes, hvo_1357 and hvo_2248, which do not show any obvious interconnection, were mutated in the majority of isolates.

\section{Materials and Methods}

\subsection{Strains and Chemicals}

$H f x$. volcanii transposon library mutants [36], as well as the wild-type strain H26 ( $D$ pyrE derivative of DS2) [43], were grown at $45^{\circ} \mathrm{C}$ in a semi-defined $H f x$. volcanii Casamino Acids (Hv-Cab) medium supplemented with uracil ( $50 \mu \mathrm{g} \mathrm{mL}{ }^{-1}$ final concentration) [44]. Cells were cultivated in either a liquid medium (orbital shaker at $250 \mathrm{rpm}$ ) or on solid (1.5\% agar) or semi-solid (0.35\% agar) plates. Difco agar was purchased from Becton, Dickinson, and Company (Becton, Dickinson, and Company, Franklin Lakes, NJ, USA). Casamino Acids were purchased from Sigma (Sigma-Aldrich, Saint Louis, MO, USA). To ensure equal agar concentrations in all plates, the agar was completely dissolved in the media prior to autoclaving, and the autoclaved media were stirred before plates were poured. For genomic DNA extraction, the Thermo Scientific GeneJET Genomic DNA Purification kit (Thermo Fisher Scientific, Waltham, MA, USA) was used.

\subsection{Screens for Hfx. volcanii Hypermotility Mutants by Stabbing Individual Tn-Mutants}

Single colonies of a $H f x$. volcanii Tn-library were stabbed into $0.35 \%$ motility agar plates with toothpicks ( 24 or 50 stabs per plate). Plates were then placed on top of a damp paper towel in a plastic container with a loosely closed lid and incubated for two to four days at $45^{\circ} \mathrm{C}$. Cells from the edge of motility halos that were at least 1.3 times the radius of H26 (wild-type) were picked with a toothpick and streaked onto solid agar plates. Cells from single colonies of the streak were re-stabbed into new motility agar plates. Each 
motility agar plate was stabbed with two mutants and two wild-type samples. Mutants whose halos still formed a radius at least 1.3 times the size of that of the wild-type control (average of at least three replicates) were grown in a liquid medium for DNA isolation and sequencing.

\subsection{Hypermotility Mutant Selection by Streaking Cells of the Tn-Library across the Center of a Motility Agar Plate and Isolation of Cells That Migrated the Farthest}

The Hfx. volcanii Tn-library was amplified and the strains were pooled. A total of $15 \mu \mathrm{L}$ of this pool $\left(10^{6}\right.$ cells $\left./ \mathrm{ml}\right)$ was streaked in a straight line across a $0.35 \%$ motility agar plate. Motility agar plates were placed on top of a damp paper towel in a plastic container with a loosely closed lid and incubated at $45^{\circ} \mathrm{C}$ for seven to eleven days. Hfx. volcanii Tn-insertion mutants from the outer edge of motility halos farthest away from the streak were picked with a toothpick and streaked onto solid agar plates. Cells from single colonies of the streak were re-stabbed into new motility agar plates to confirm hypermotility. Each motility agar plate was stabbed with two mutants and two wild-type samples. Mutants whose halos formed a radius at least 1.3 times the size of that of the wild-type control (average of at least four replicates) were grown in a liquid medium for DNA isolation and sequencing.

\subsection{Genome Sequencing}

Sequencing libraries were prepared from DNA extractions with the Nextera XT DNA Library Preparation Kit (Illumina, Catalog \#FC-131-1096, San Diego, CA, USA). After quantification on Qubit, $1 \mathrm{ng}$ of input was used for library preparation. Completed libraries were quantified on Qubit and assessed for quality on an Agilent 4200 Tapestation. Sequencing was performed on an Illumina MiniSeq with a Mid Output Kit and paired-end, 150 cycle reads.

\subsection{Detection of Primary and Secondary Genome Alterations}

For the detection of genome alterations, a reference genome sequence is required. This was created in silico in a multistep process based on genomic alterations to the available

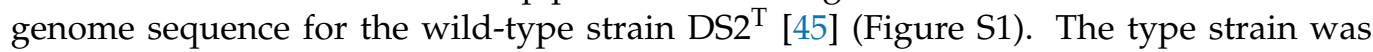
cured for plasmid pHV2 [46], resulting in strain DS70. During curing, plasmid pHV4 was inadvertently integrated into the chromosome [47]. Strain DS70 was converted to the $\triangle$ pyrE2 strain H26 [43]. This strain was subjected to deep sequencing, which led to the detection of a few additional SNPs [47]. The genome sequence of strain H26 was kindly provided by Thorsten Allers (University of Nottingham, UK). Strain H26 is the parent of strain H295 ( $\Delta$ rad50 $\Delta m r e 11 \Delta \operatorname{trp} A)$ [48], and its construction is described in Figure S1. The additional mutations ( $\Delta$ rad50 $\Delta$ mre11 and $\Delta \operatorname{trp} A$ ) introduced into the H26 genome sequence to obtain a reference sequence of $\mathrm{H} 295$ were as described in [48].

Illumina reads were imported into Geneious Prime, trimmed using BBDuk (default settings) from the BBTools package [49] and mapped to the genome sequence of the parental strain (strain H295) using the Bowtie2 mapper available within Geneious Prime. Tn-insertions were identified by searching for transposon-specific terminal sequences and the insertion point was noted as the first base differing from that of the genome. Other changes were identified by manual scanning of the assembly within Geneious.

During an initial analysis, we detected genome alterations which occurred in all strains: (a) An A>T mutation at pos 521,827 of strain H295 (357 nt from start of HVO_A0011 on the integrated plasmid pHV4; corresponds to pos 12,162 on pHV4). (b) For pHV3 (GenBank accession CP001953), we detected six distinct mutations, a G>A at pos 26,672 and five others which all occur in the gene encoding HVO_B0311 (G>C at pos 359,036, G insertion after pos 359,039, G insertion after pos 359,057, G insertion after pos 359,101, C insertion after pos 359,134$)$. The regions affected by mutations match to those from resequencing of the Hfx. volcanii type strain genome (GenBank accession AOHU01000021) [50]. These general mutations were assumed to exist in the parental strain. They may have been introduced either during generation of the Tn-library or might be attributed to mutations that had 
occurred during serial passage of the parent strains in the laboratory, while generating strain H295. We updated the reference genome sequence (H295mod1) and analyzed for mutations compared to that genome version. FastA files with these reference sequences (chromosome and plasmid pHV3) are provided as Files S1 and S2, respectively.

Mutants were of two principle types: (a) Every mutant in a Tn-library needs to show a transposon integration site, which we refer to as primary mutation. (b) There may be additional genomic alterations, which are unpredicted and which we refer to as secondary mutations (Table 1). All primary and secondary mutations are listed in Table S1.

\subsection{Bioinformatic Analyses}

Ortholog analysis was performed using OrthoDB [51,52]. Gene synteny was analyzed with SyntTax [53], and by the "conserved neighborhood" option available at the DOE Joint Genome Institute (JGI) IMG/MER database [54,55]. The 3D structure prediction was attempted with Phyre2 [56].

\section{Results and Discussion}

The isolation of non-motile mutants from a $H f x$. volcanii transposon insertion library has revealed that genes outside the core archaellum cluster may have a major impact on motility. The molecular basis of such regulatory components is still under study. In a complementary approach, using two distinct strategies, we set out to isolate hypermotile Tn-mutants, aiming to identify additional components required for archaella function or regulation.

\subsection{Screening for Hypermotility by Stabbing Individual Strains}

As a first screening method, we stabbed individual mutants from the Tn-library onto motility plates, incubated these for two to four days, and looked for colonies that had formed unusually large motility halos (Figure 1).

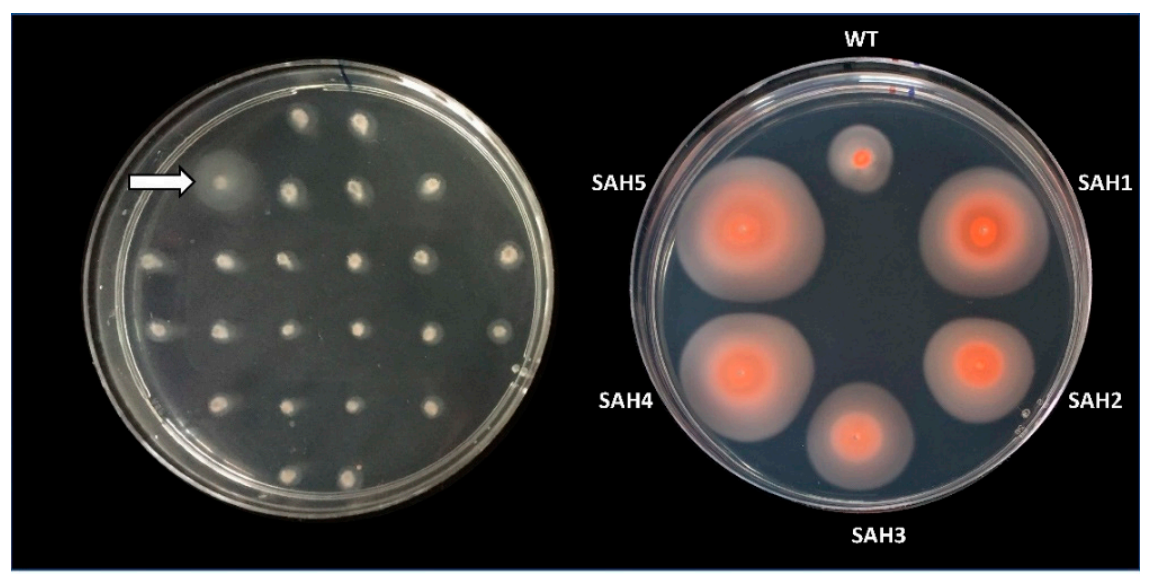

Figure 1. Hypermotility screen. Cells from Hfx. volcanii mutants of a transposon insertion library (Tn-library) were stabbed into a motility agar plate $\left(0.35 \%\right.$ agar) and incubated for 48 hours at $45^{\circ} \mathrm{C}$ (left). To confirm the hypermotile phenotype of Tn-mutants with larger halos (e.g., marked by arrow), cells from the outer edge of the motility halo were re-streaked onto solid agar plates. Cells from individual colonies were then re-stabbed into motility agar plates and incubated for 90 hours at $45^{\circ} \mathrm{C}$ (right). Isolates with a halo size radius at least 1.3 times that of the wild-type strain were considered hypermotile and were subjected to Illumina sequencing. Right image was taken after 10 days at room temperature. Halo size did not increase but they did become darker due to an increase in pigment production.

Out of approximately 1250 stabbed Tn-mutants, five were hypermotile (SAH1-5). Whole genome Illumina sequencing revealed that each mutant had a distinct Tn-insertion site. Two mutants (SAH4, SAH5) had insertions in the same gene, hoo_2248, albeit at 
different positions (Table 1). Whole genome Illumina sequencing also uncovered that several mutants were affected by unanticipated, secondary genome alterations. Such secondary alterations were encountered in two of the five isolates (SAH3, SAH5) (Table 1 and Table S1). SAH5 lost a few spacers from a CRISPR array, which is unlikely to affect motility. In contrast, SAH3 lost two long sections of plasmid pHV4, totaling $230 \mathrm{~kb}$, making it difficult to determine whether the hypermotility phenotype is due to the original transposon insertion (into the gene encoding HVO_0430) or due to the secondary genome alterations, which eliminate the genes for many proteins (HVO_A0014 to HVO_A0119 and HVO_A0279A to HVO_A0412).

Table 1. Genome alterations in hypermotile $H f x$. volcanii Tn-isolates.

\begin{tabular}{|c|c|c|c|c|c|}
\hline \multicolumn{6}{|c|}{ Affected Genes ${ }^{1}$} \\
\hline $\begin{array}{l}\text { Tn-Insertion } \\
\text { Position }^{2}\end{array}$ & $\begin{array}{l}\text { Total } \\
\text { Count }\end{array}$ & Primary & Secondary & Count & Isolates $^{3}$ \\
\hline \multirow{3}{*}{$2,734,510$} & \multirow{3}{*}{ - } & HVO_2248 & HVO_1357 & 1 & MC3 \\
\hline & & HVO_2248 & - & 1 & MC50 \\
\hline & & HVO_2248 & yes & 1 & SAH4 \\
\hline \multirow{3}{*}{$2,734,434$} & \multirow{3}{*}{9} & HVO_2248 & HVO_1357 & 1 & MC14 \\
\hline & & HVO_2248 & - & 6 & SAH5, MC9, 15, 16, 17, 26 \\
\hline & & HVO_2248 & yes & 2 & MC27, 49 \\
\hline \multirow{3}{*}{$2,734,755$} & \multirow{3}{*}{10} & $\begin{array}{c}\text { HVO_2248 } \\
\text { (Near) }\end{array}$ & HVO_1357, + & 3 & MC1, 28, 31 \\
\hline & & $\begin{array}{c}\text { HVO_2248 } \\
\text { (Near) }\end{array}$ & - & 4 & $\mathrm{MC} 8,23,30,35$ \\
\hline & & $\begin{array}{c}\text { HVO_2248 } \\
\text { (Near) }\end{array}$ & yes & 3 & $\mathrm{MC} 4,6,7$ \\
\hline $1,147,136$ & 2 & HVO_0576 & HVO_2248, + & 2 & MC36, 45 \\
\hline $2,404,062$ & 1 & HVO_1926 & HVO_2248, + & 1 & MC34 \\
\hline $2,723,422$ & 1 & HVO_2229 & HVO_2248 & 1 & MC54 \\
\hline $2,871,511$ & 1 & HVO_2377 & HVO_2248, + & 1 & MC44 \\
\hline 621,497 & 1 & HVO_A0546 & HVO_2248, + & 1 & MC52 \\
\hline \multirow{3}{*}{$1,867,146$} & \multirow{3}{*}{4} & HVO_1357 & HVO_2248, + & 1 & MC11 \\
\hline & & HVO_1357 & - & 1 & MC19 \\
\hline & & HVO_1357 & yes & 2 & MC24, 37 \\
\hline \multirow{2}{*}{$1,867,189$} & \multirow{2}{*}{13} & HVO_1357 & - & 7 & MC5, 10, 22, 29, 40, 41, 48 \\
\hline & & HVO_1357 & yes & 6 & $\mathrm{MC} 2,12,20,21,25,33$ \\
\hline $1,865,880$ & 2 & HVO_1357 & - & 2 & $\mathrm{MC} 42,46$ \\
\hline $2,678,278$ & 1 & $\begin{array}{c}\text { HVO_2176 } \\
\text { (Near) }\end{array}$ & - & 1 & SAH1 \\
\hline $2,225,641$ & 1 & HVO_1726 & - & 1 & SAH2 \\
\hline $1,020,227$ & 1 & HVO_0430 & extensive & 1 & SAH3 \\
\hline $3,126,642$ & 1 & HVO_2649 & extensive & 1 & MC47 \\
\hline
\end{tabular}

${ }^{1}$ Mutations are classified according to the genes which they affect ("HVO_2248 or HVO_1357" or "Other genes") and according to primary (Tn-insertion) or secondary (secondary genome alterations). Mutations affecting HVO_2248 are highlighted blue, those affecting HVO_1357 are green. Other genes are highlighted yellow if they are considered relevant. Grey background color (indicating not to be relevant) is used for primary mutations in other genes if HVO_2248 is affected by a secondary genome alteration. Grey background color is also the case when secondary genome alterations are extensive. ${ }^{2} \mathrm{Tn}$-insertion position refers to the first change compared to the chromosomal sequence of strain $\mathrm{H} 295$ (see Methods). For each Tn-insertion position, the total number of isolates is specified (Total Count). Subclassification is used when some isolates are affected only by Tn-insertion, some have secondary genome alterations affecting either HVO_2248 or HVO_1357, possibly also affecting other genes (indicated by + ), and/or some have only other genes affected by secondary genome alterations. The number of isolates for each subcategory is given (Count). ${ }^{3}$ Isolate names starting with SAH indicate the 1st screen (stabbing individual colonies on hypermotility plates). Isolate names starting with MC indicate the 2nd screen (central streak of the amplified library, picking strains that had moved farthest). If multiple MC isolates are listed, MC is omitted except for the first isolate. Full details for each isolate are provided in Table S1. 
HVO_1726 contains a helix-turn-helix (HTH) domain at the N-terminus and thus may function as a transcriptional regulator. The adjacent genes are one of the Orc1-type DNA replication protein paralogs and one of the TATA-binding transcription initiation factor paralogs.

HVO_2176 has an assigned HalOD1 domain according to InterPro. This domain may be found in combination with a response regulator receiver domain [57]. HVO_2175, annotated as sph3, encodes a structural maintenance of chromosomes (SMC)-like protein. The SMC-like protein Sph1 from Hbt. salinarum (OE5212F, the ortholog of HVO_A0180) resulted in elongated rods when overproduced in its native host. When heterologously expressed in $H f x$. volcanii, it leads to rod formation compared to predominantly pleomorphic disks in the non-transformed strain [58]. The other adjacent gene is samp3, which encodes a ubiquitin-like protein that is covalently attached to target proteins [59].

HVO_2248, which was also identified dominantly in an alternative screen (see below), belongs to the genomic dark matter as it lacks characterized homologs and has no assigned InterPro domains. It is predicted to be a cytoplasmic protein. As it was identified in all seven whole proteome datasets, which were reanalyzed within the Archaeal Proteome project, it is considered to be crucial under a variety of experimental conditions [60]. Homologs of HVO_2248 are only found in the taxonomic class Halobacteria and neither in other Euryarchaeota nor in other Archaea. It is encoded in only about one-third of the Halobacteria (66 of 166) according to orthoDB [51]. The genes in the vicinity of the $H f x$. volcanii DS2 genome have no obvious relation to motility, and conservation of gene synteny is restricted to closely-related species. However, we note that the gene for a methylaccepting chemotaxis protein (MCP, commonly referred to as $\mathrm{Htr}$, halobacterial transducer protein) is intercalated right next to that encoding HVO_2248 in several Haloferax species, such as the ARA6 strain of Haloferax gibbonsii. We analyzed 25 genomes from the genus Haloferax and in half of them (12 of 25), an htr gene is present while no such gene is found in the other half (Figure S2). Outside the genus Haloferax, only a single genome was found to contain a $h t r$ gene in a similar arrangement, that of Halogeometricum borinquense, which, however, shows additional differences. The Phyre2 server could not predict a 3D structure model of high confidence. Thus, although over $1200 \mathrm{Tn}$-insertion mutants were screened, only three candidate genes (or gene regions) for hypermotility were identified: $h v o \_1726$ (SAH2), the region between hvo_2175 and hvo_2176 (SAH1), and hvo_2248 (SAH4 and SAH5).

\subsection{Selection for Hypermotility by Picking Cells That Moved Farthest from a Central Streak}

In order to screen a significantly larger number of Tn-mutants in a short period of time, we designed a different method, which involves auto-selection of hypermotile cells. We streaked a pool of strains from the amplified Tn-library across the motility agar plate and picked cells that had moved farthest from the initial streak (Figure 2). Upon re-streaking cells from the edge of the halos on solid agar plates, single colonies were isolated and analyzed for hypermotility. 


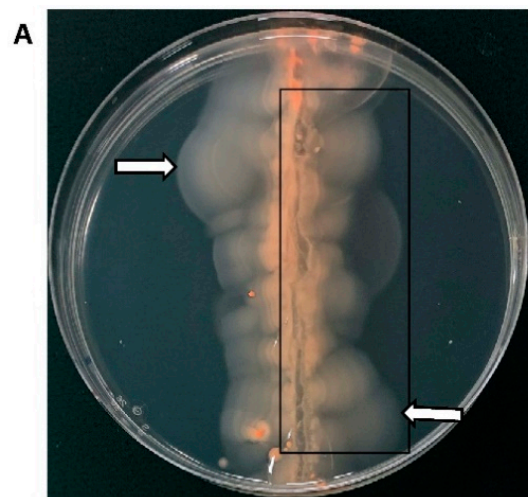

11 days

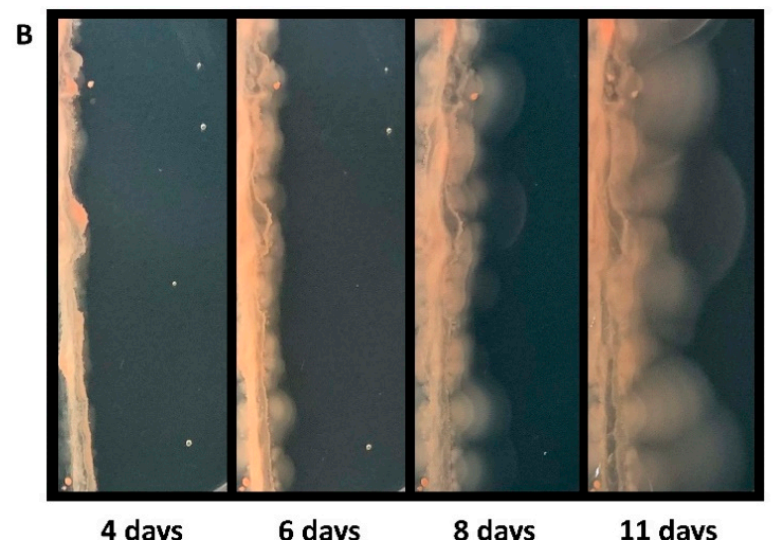

4 days

6 days

8 days

11 days

Figure 2. Selection of hypermotile isolates. (A) Pooled cells $\left(15 \mu \mathrm{L}, 10^{6}\right.$ cells $\left./ \mathrm{ml}\right)$ from the $H f x$. volcanii Tn-library were streaked across a motility agar plate and incubated at $45^{\circ} \mathrm{C}$ for eleven days. The white arrows mark examples of positions of halos farthest away from the streak from which cells were re-streaked onto solid agar plates. Cells from individual colonies were re-stabbed into motility agar plates. Isolates with a halo size radius at least 1.3 times that of the wild-type strain were considered hypermotile and were subjected to Illumina sequencing. (B) The progression of the motility halos over eleven days can be seen in the panels going from left to right: four days, six days, eight days, and eleven days after streaking.

It should be noted that each Tn-mutant will be represented multiple times in the pool that is streaked, and thus such a mutant may be isolated multiple times during this screen. However, multiple isolations of the same Tn-mutant, taken from well-separated positions of the agar plate, should occur only if this specific mutation leads to an especially strong manifestation of the phenotype, which is selected for (Figure S3). Of 54 samples isolated from the screen, 49 retained hypermotility after clonal isolation. The sequence data returned for three strains were insufficient for analysis, and the genetic changes of the remaining 46 mutants were determined and are summarized in Table 1 and Table S1. They represent 13 distinct transposon insertion sites, some of which have been isolated several times (one Tn-mutant 13 times, one Tn-mutant 10 times, one Tn-mutant eight times). However, even in those cases where the transposon was found inserted at the same position and thus is likely to represent the same original mutant, distinct secondary genome alterations were encountered in some cases, which confirms the independence of their isolation, especially when picked from distinct plates. The secondary alterations might have occurred during the growth from the initial streak position to the final location where the isolate was picked. Alternatively, the streaked transposon library might have already been heterogeneous due to its amplification. Several isolates had not only the same Tn-insertion site, but also identical secondary genome alterations, as shown in Table 1 and Table S1.

HVO_2248 was very prominently identified in this screen, with three distinct Tninsertion sites within the gene or immediately upstream and a total of 20 isolates. For several Tn-insertion sites, the mutant was independently selected several times (10 times; eight times; twice) (Table 1). The two transposon insertion sites within hvo_2248 that had already been identified in the stabbing screen (SAH4, SAH5) were re-isolated in this independent screen.

Many of the isolates carried additional secondary genome alterations, among those being mutations in hvo_1357 (see below). On the other hand, many mutants that had a Tn-insertion into other genes also carried a mutation of $h v o \_2248$ as a secondary genome alteration. However, because several of the isolates with the Tn-insertion into hvo_2248 lack any secondary genome alteration, we consider this gene to be directly responsible for the hypermotility phenotype. 
The other gene prominently retrieved was hoo_1357, with a total of 19 isolates representing three Tn-insertion sites that were isolated multiple times (13 times; four times; twice) (Table 1). HVO_1357 and the proteins encoded by its genomic neighbors (HVO_1356 and HVO_1358) belong to an extended two-component regulatory system that probably regulates genomic gene expression (Figure 3). HVO_1356 is a sensor box histidine kinase that also has a GAF and a PAS domain. HVO_1358 is a receiver box response regulator. HVO_1357 itself is a multidomain protein; it has a receiver domain at the N-terminus, with the phosphorylatable aspartate (Asp) residue being conserved (Asp-67). It also has a Bat-type HTH domain (HTH-10) at its C-terminus. This HTH domain subtype is known from the Hbt. salinarum bat gene (OE3101R), which activates the bop gene that encodes bacteriorhodopsin [61,62]. HVO_1357 carries an additional Bat-specific domain (IPR031803), a GAF domain (IPR029016), and a HalX domain (IPR013971). Thus, HVO_1357 is likely part of a signal-dependent gene regulation cascade and may be directly involved in the transcriptional regulation of target genes. As several of the isolates with the Tn-insertion into hvo_1357 lack any secondary genome alteration, we consider this gene to be directly responsible for the hypermotility phenotype.

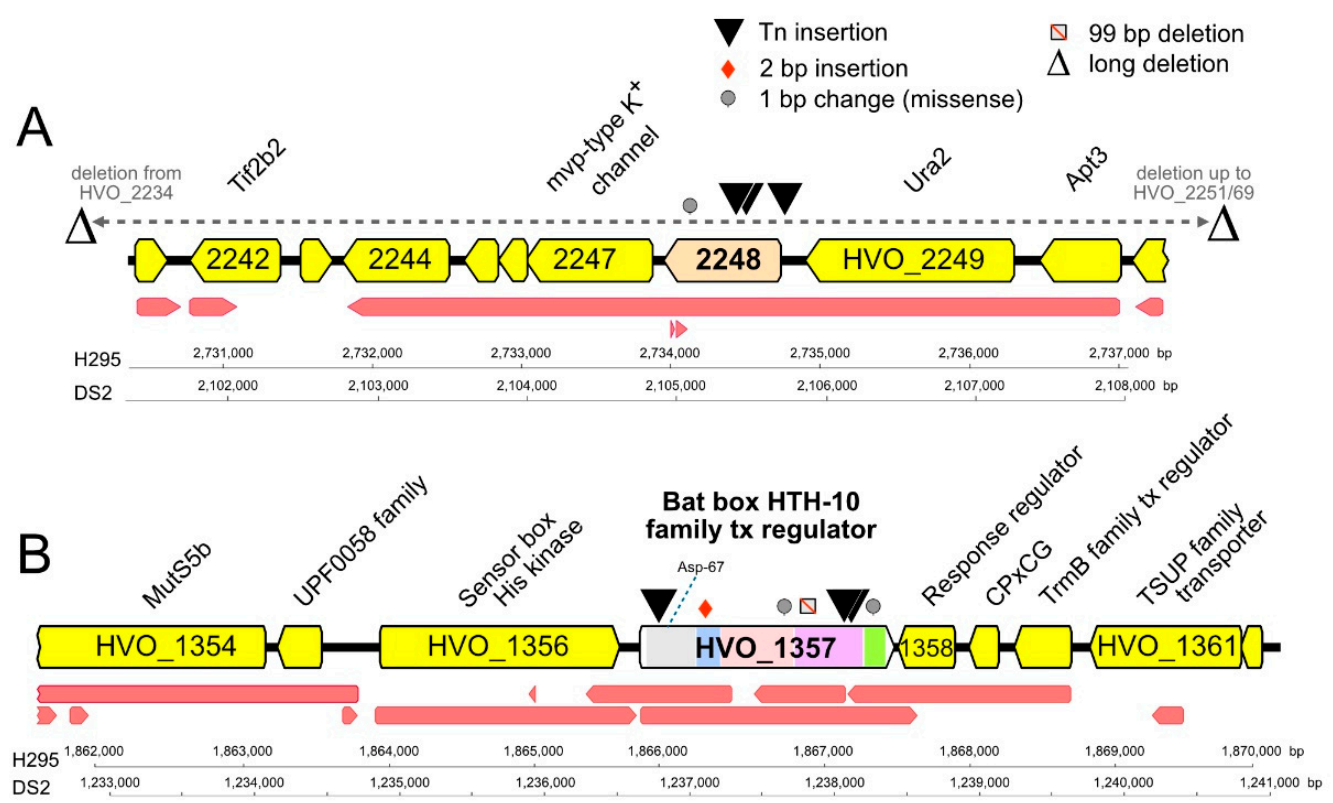

Figure 3. Mutations, domains, and genomic neighborhood of HVO_2248 and HVO_1357. Tninsertions and other mutations detected in the chromosomal genes coding for HVO_2248 (A) and HVO_1357 (B) of hypermotile $H f x$. volcanii mutants. The types and positions of mutations are indicated by symbols above HVO_2248 and HVO_1357 (key at top right). Protein product names are given above gene arrows, and locus_tag numbers are shown within arrows (often without prefix HVO for space reasons). The transcript map reported by [63] is represented by red arrows below each gene map. Scale bars and nucleotide numbering for strains H295 and DS2 are shown below each map. Panel A. HVO_2248 and its immediate gene neighborhood. Ura2, xanthine/uracil permease family transport protein; Apt3, purine phosphoribosyltransferase (adenine phosphoribosyltransferase, xanthine-guanine phosphoribosyltransferase); Tif2b2, translation initiation factor aIF-2 beta subunit/probable RNA-binding protein. Panel B. HVO_1357 and its immediate gene neighborhood. MutS5b, DNA mismatch repair protein MutS; response regulator, receiver box response regulator; CPxCG, small CPxCG-related zinc finger protein; tx, transcription. Colored regions within HVO_1357 denote conserved protein domains: grey, signal transduction response regulator (IPR001789); light blue, HalX (IPR013971); pink, GAF (IPR029016); purple, BAT (IPR031803); green, HTH-10 (IPR007050). The position of the conserved phosphorylatable Asp- 67 within the receiver domain is indicated by a blue dotted line. 
Six other isolates had a Tn-insertion into distinct genes, but in each case, hvo_2248 was affected by a secondary genome alteration. Only one isolate was completely independent of these two genes and had a Tn-insertion into hvo_2269 but additionally lacked two long regions, totaling to $230 \mathrm{~kb}$, from the integrated plasmid pHV4 (the same regions deleted as in SAH3), and thus was not further analyzed. Thus, in summary, 45 of the 46 mutants had either a mutation associated with HVO_1357 (19) or HVO_2248 (25), and five had both Of the five mutants that had mutations in both HVO_1357 and HVO_2248, none showed a further increased hypermotility phenotype compared to mutants with just one of the genes mutated. HVO_2248 and HVO_1357 appear to be critical in direct or indirect motility regulation and it is very possible that they interact with each other in this process.

\section{Conclusions}

Using distinct screening and selection procedures, we identified a large number of hypermotile isolates derived from a transposon insertion library. The selection especially allowed for the rapid isolation of many hypermotile isolates. Whole-genome Illiumina sequencing uncovered that many, but not all, of the isolates carried secondary genome alterations, underscoring the importance of extending mutant analysis to whole-genome sequencing. Our results reveal that the genes encoding HVO_1357 and HVO_2248 were affected in nearly all hypermotile isolates, either alone or in combination. While HVO_1357 is likely participating in a two-component regulatory system, probably acting as a transcriptional regulator, HVO_2248 is part of the genomic dark matter, with as yet no InterPro domain assigned and no clues from 3D structure prediction nor gene synteny analysis, but a subtle link to chemotaxis due to an $h t r$ gene in the immediate vicinity of about half of the genomes from the genus Haloferax. Nevertheless, the strong overrepresentation of these two genes in a large set of independently obtained mutants highlights the likely importance of both genes in $H f x$. volcanii hypermotility. Thus, we have opened the road to detailed experimental analyses and a deep understanding of this process.

Supplementary Materials: The following are available online at https:/ /www.mdpi.com/2073-4 425/12/1/58/s1, Figure S1: Generation of Hfx. volcanii reference genome for Tn-insertion mutant genome analysis, Figure S2: Gene Ortholog Neighborhoods output using HVO_2248 of Hfx. volcanii DS2 as the reference, Figure S3: Motility plates used to select for hypermotile mutants MC1-54, Table S1: Primary and secondary mutations in hypermotile Hfx. volcanii Tn-isolates, File S1: Hfx. volcanii H295mod1_CHR reference sequence H295mod1 of the chromosome (with integrated plasmid pHV4), File S2: Hfx. volcanii H295mod1 pHV3 reference sequence H295mod1 of plasmid pHV3.

Author Contributions: M.C. and S.A. carried out the selection and the screen for hypermotile mutants, respectively. M.C., S.A. and H.S. characterized the Tn-mutants. E.K. and D.P.B. carried out the genome sequencing. A.B.I. carried out initial Tn-insertion analysis. M.D.-S. and F.P. carried out detailed genome and homology analyses. Results were interpreted and the manuscript was written through contributions of all authors. M.C. and M.P. developed the idea for the project and M.P. supervised it. All authors have given approval to the final version of the manuscript.

Funding: M.P., S.A., H.S. and M.C. were supported by the National Science Foundation grant 1817518. MC also received summer research support from the Spring 2019 Pincus-Magaziner Family Undergraduate Research, the Spring 2019 College Alumni Society, the Spring 2020 Junior Jumpstart and Spring 2020 Benjamin Franklin Scholars Summer Research. A.B.I was supported by the Spring 2018 Pincus-Magaziner Family Undergraduate Research and Travel Fund from the College Alumni Society.

Institutional Review Board Statement: Not applicable.

Informed Consent Statement: Not applicable.

Data Availability Statement: Data are contained within the article or supplementary material.

Acknowledgments: We thank Stefan Schulze and Jack Beltz for helpful discussions.

Conflicts of Interest: The authors declare no conflict of interest. 


\section{References}

1. Jung, J.; Kim, J.-S.; Taffner, J.; Berg, G.; Ryu, C.-M. Archaea, Tiny Helpers of Land Plants. Comput. Struct. Biotechnol. J. 2020, 18, 2494-2500. [CrossRef]

2. Offre, P.; Spang, A.; Schleper, C. Archaea in Biogeochemical Cycles. Annu. Rev. Microbiol. 2013, 67, 437-457. [CrossRef]

3. Spang, A.; Caceres, E.F.; Ettema, T.J.G. Genomic Exploration of the Diversity, Ecology, and Evolution of the Archaeal Domain of Life. Science 2017, 357, 1-10. [CrossRef]

4. Borrel, G.; Brugère, J.-F.; Gribaldo, S.; Schmitz, R.A.; Moissl-Eichinger, C. The Host-Associated Archaeome. Nat. Rev. Microbiol. 2020, 18, 622-636. [CrossRef] [PubMed]

5. Kim, J.Y.; Whon, T.W.; Lim, M.Y.; Kim, Y.B.; Kim, N.; Kwon, M.-S.; Kim, J.; Lee, S.H.; Choi, H.-J.; Nam, I.-H.; et al. The Human Gut Archaeome: Identification of Diverse Haloarchaea in Korean Subjects. Microbiome 2020, 8, 114. [CrossRef] [PubMed]

6. Alam, M.; Oesterhelt, D. Purification, Reconstitution and Polymorphic Transition of Halobacterial Flagella. J. Mol. Biol. 1987, 194, 495-499. [CrossRef]

7. Albers, S.-V.; Jarrell, K.F. The Archaellum: An Update on the Unique Archaeal Motility Structure. Trends Microbiol. 2018, 26, 351-362. [CrossRef]

8. Beeby, M.; Ferreira, J.L.; Tripp, P.; Albers, S.-V.; Mitchell, D.R. Propulsive Nanomachines: The Convergent Evolution of Archaella, Flagella and Cilia. FEMS Microbiol. Rev. 2020, 44, 253-304. [CrossRef]

9. Meister, M.; Lowe, G.; Berg, H.C. The Proton Flux through the Bacterial Flagellar Motor. Cell 1987, 49, 643-650. [CrossRef]

10. Streif, S.; Staudinger, W.F.; Marwan, W.; Oesterhelt, D. Flagellar Rotation in the Archaeon Halobacterium salinarum Depends on ATP. J. Mol. Biol. 2008, 384, 1-8. [CrossRef]

11. Albers, S.-V.; Szabó, Z.; Driessen, A.J.M. Archaeal Homolog of Bacterial Type IV Prepilin Signal Peptidases with Broad Substrate Specificity. J. Bacteriol. 2003, 185, 3918-3925. [CrossRef] [PubMed]

12. Bardy, S.L.; Jarrell, K.F. Cleavage of Preflagellins by an Aspartic Acid Signal Peptidase Is Essential for Flagellation in the Archaeon Methanococcus voltae. Mol. Microbiol. 2003, 50, 1339-1347. [CrossRef] [PubMed]

13. Peabody, C.R.; Chung, Y.J.; Yen, M.-R.; Vidal-Ingigliardi, D.; Pugsley, A.P.; Saier, M.H. Type II Protein Secretion and Its Relationship to Bacterial Type IV Pili and Archaeal Flagella. Microbiol. Read. Engl. 2003, 149, 3051-3072. [CrossRef] [PubMed]

14. Shahapure, R.; Driessen, R.P.; Haurat, M.F.; Albers, S.V.; Dame, R.T. The Archaellum: A Rotating Type IV Pilus. Mol. Microbiol. 2014, 91, 716-723. [CrossRef]

15. Szabó, Z.; Stahl, A.O.; Albers, S.-V.; Kissinger, J.C.; Driessen, A.J.M.; Pohlschröder, M. Identification of Diverse Archaeal Proteins with Class III Signal Peptides Cleaved by Distinct Archaeal Prepilin Peptidases. J. Bacteriol. 2007, 189, 772-778. [CrossRef]

16. Makarova, K.S.; Koonin, E.V.; Albers, S.-V. Diversity and Evolution of Type IV Pili Systems in Archaea. Front. Microbiol. 2016, 7, 667. [CrossRef]

17. Patenge, N.; Berendes, A.; Engelhardt, H.; Schuster, S.C.; Oesterhelt, D. The Fla Gene Cluster Is Involved in the Biogenesis of Flagella in Halobacterium salinarum. Mol. Microbiol. 2001, 41, 653-663. [CrossRef]

18. Thomas, N.A.; Mueller, S.; Klein, A.; Jarrell, K.F. Mutants in FlaI and FlaJ of the Archaeon Methanococcus voltae Are Deficient in Flagellum Assembly. Mol. Microbiol. 2002, 46, 879-887. [CrossRef]

19. Chaudhury, P.; Neiner, T.; D’Imprima, E.; Banerjee, A.; Reindl, S.; Ghosh, A.; Arvai, A.S.; Mills, D.J.; Does, C.; Tainer, J.A.; et al. The Nucleotide-dependent Interaction of FlaH and FlaI Is Essential for Assembly and Function of the Archaellum Motor. Mol. Microbiol. 2016, 99, 674-685. [CrossRef]

20. Reindl, S.; Ghosh, A.; Williams, G.J.; Lassak, K.; Neiner, T.; Henche, A.-L.; Albers, S.-V.; Tainer, J.A. Insights into FlaI Functions in Archaeal Motor Assembly and Motility from Structures, Conformations, and Genetics. Mol. Cell 2013, 49, 1069-1082. [CrossRef]

21. Nutsch, T.; Oesterhelt, D.; Gilles, E.D.; Marwan, W. A Quantitative Model of the Switch Cycle of an Archaeal Flagellar Motor and Its Sensory Control. Biophys. J. 2005, 89, 2307-2323. [CrossRef] [PubMed]

22. Nutsch, T.; Marwan, W.; Oesterhelt, D.; Gilles, E.D. Signal Processing and Flagellar Motor Switching During Phototaxis of Halobacterium salinarum. Genome Res. 2003, 13, 2406-2412. [CrossRef] [PubMed]

23. Kinosita, Y.; Uchida, N.; Nakane, D.; Nishizaka, T. Direct Observation of Rotation and Steps of the Archaellum in the Swimming Halophilic Archaeon Halobacterium salinarum. Nat. Microbiol. 2016, 1, 16148. [CrossRef] [PubMed]

24. Koch, M.K.; Staudinger, W.F.; Siedler, F.; Oesterhelt, D. Physiological Sites of Deamidation and Methyl Esterification in Sensory Transducers of Halobacterium salinarum. J. Mol. Biol. 2008, 380, 285-302. [CrossRef] [PubMed]

25. Quax, T.E.F.; Albers, S.-V.; Pfeiffer, F. Taxis in Archaea. Emerg. Top. Life Sci. 2018, 2, 535-546. [CrossRef]

26. Rudolph, J.; Oesterhelt, D. Chemotaxis and Phototaxis Require a CheA Histidine Kinase in the Archaeon Halobacterium salinarium. EMBO J. 1995, 14, 667-673. [CrossRef]

27. Rudolph, J.; Oesterhelt, D. Deletion Analysis of the Che Operon in the Archaeon Halobacterium salinarium. J. Mol. Biol. 1996, 258, 548-554. [CrossRef]

28. Schlesner, M.; Miller, A.; Streif, S.; Staudinger, W.F.; Müller, J.; Scheffer, B.; Siedler, F.; Oesterhelt, D. Identification of ArchaeaSpecific Chemotaxis Proteins Which Interact with the Flagellar Apparatus. BMC Microbiol. 2009, 9, 56. [CrossRef]

29. Schlesner, M.; Miller, A.; Besir, H.; Aivaliotis, M.; Streif, J.; Scheffer, B.; Siedler, F.; Oesterhelt, D. The Protein Interaction Network of a Taxis Signal Transduction System in a Halophilic Archaeon. BMC Microbiol. 2012, 12, 272. [CrossRef]

30. Wong-Ng, J.; Celani, A.; Vergassola, M. Exploring the Function of Bacterial Chemotaxis. Curr. Opin. Microbiol. 2018, 45, 16-21. [CrossRef] 
31. Yang, W.; Briegel, A. Diversity of Bacterial Chemosensory Arrays. Trends Microbiol. 2020, 28, 68-80. [CrossRef] [PubMed]

32. Quax, T.E.F.; Altegoer, F.; Rossi, F.; Li, Z.; Rodriguez-Franco, M.; Kraus, F.; Bange, G.; Albers, S.-V. Structure and Function of the Archaeal Response Regulator CheY. Proc. Natl. Acad. Sci. USA 2018, 115, E1259-E1268. [CrossRef] [PubMed]

33. Li, Z.; Kinosita, Y.; Rodriguez-Franco, M.; Nußbaum, P.; Braun, F.; Delpech, F.; Quax, T.E.F.; Albers, S.-V. Positioning of the Motility Machinery in Halophilic Archaea. mBio 2019, 10, e00377-19. [CrossRef] [PubMed]

34. Li, Z.; Rodriguez-Franco, M.; Albers, S.; Quax, T.E.F. The Switch Complex ArlCDE Connects the Chemotaxis System and the Archaellum. Mol. Microbiol. 2020, 114, 468-479. [CrossRef] [PubMed]

35. Duggin, I.G.; Aylett, C.H.S.; Walsh, J.C.; Michie, K.A.; Wang, Q.; Turnbull, L.; Dawson, E.M.; Harry, E.J.; Whitchurch, C.B.; Amos, L.A.; et al. CetZ Tubulin-like Proteins Control Archaeal Cell Shape. Nature 2015, 519, 362-365. [CrossRef] [PubMed]

36. Kiljunen, S.; Pajunen, M.I.; Dilks, K.; Storf, S.; Pohlschroder, M.; Savilahti, H. Generation of Comprehensive Transposon Insertion Mutant Library for the Model Archaeon, Haloferax volcanii, and Its Use for Gene Discovery. BMC Biol. 2014, 12, 103. [CrossRef]

37. Legerme, G.; Yang, E.; Esquivel, R.; Kiljunen, S.; Savilahti, H.; Pohlschroder, M. Screening of a Haloferax volcanii Transposon Library Reveals Novel Motility and Adhesion Mutants. Life 2016, 6, 41. [CrossRef]

38. Legerme, G.; Pohlschroder, M. Limited Cross-Complementation Between Haloferax volcanii PilB1-C1 and PilB3-C3 Paralogs. Front. Microbiol. 2019, 10, 700. [CrossRef]

39. Abdul Halim, M.F.; Pfeiffer, F.; Zou, J.; Frisch, A.; Haft, D.; Wu, S.; Tolić, N.; Brewer, H.; Payne, S.H.; Paša-Tolić, L.; et al. Haloferax volcanii Archaeosortase Is Required for Motility, Mating, and C-Terminal Processing of the S-Layer Glycoprotein. Mol. Microbiol. 2013, 88, 1164-1175. [CrossRef]

40. Hoffmann, L.; Schummer, A.; Reimann, J.; Haurat, M.F.; Wilson, A.J.; Beeby, M.; Warscheid, B.; Albers, S.-V. Expanding the Archaellum Regulatory Network-The Eukaryotic Protein Kinases ArnC and ArnD Influence Motility of Sulfolobus acidocaldarius. MicrobiologyOpen 2017, 6, e00414. [CrossRef]

41. Maier, L.-K.; Benz, J.; Fischer, S.; Alstetter, M.; Jaschinski, K.; Hilker, R.; Becker, A.; Allers, T.; Soppa, J.; Marchfelder, A. Deletion of the Sm1 Encoding Motif in the Lsm Gene Results in Distinct Changes in the Transcriptome and Enhanced Swarming Activity of Haloferax Cells. Biochimie 2015, 117, 129-137. [CrossRef] [PubMed]

42. Tripepi, M.; Esquivel, R.N.; Wirth, R.; Pohlschröder, M. Haloferax volcanii Cells Lacking the Flagellin FlgA2 Are Hypermotile. Microbiology 2013, 159, 2249-2258. [CrossRef] [PubMed]

43. Allers, T.; Ngo, H.-P.; Mevarech, M.; Lloyd, R.G. Development of Additional Selectable Markers for the Halophilic Archaeon Haloferax volcanii Based on the LeuB and TrpA Genes. Appl. Environ. Microbiol. 2004, 70, 943-953. [CrossRef] [PubMed]

44. de Silva, R.T.; Abdul-Halim, M.F.; Pittrich, D.A.; Brown, H.J.; Pohlschroder, M.; Duggin, I.G. Improved Growth and Morphological Plasticity of Haloferax volcanii. bioRxiv 2020, 1-29. [CrossRef]

45. Hartman, A.L.; Norais, C.; Badger, J.H.; Delmas, S.; Haldenby, S.; Madupu, R.; Robinson, J.; Khouri, H.; Ren, Q.; Lowe, T.M.; et al. The Complete Genome Sequence of Haloferax volcanii DS2, a Model Archaeon. PLoS ONE 2010, 5, e9605. [CrossRef]

46. Wendoloski, D.; Ferrer, C.; Dyall-Smith, M.L. A New Simvastatin (Mevinolin)-Resistance Marker from Haloarcula hispanica and a New Haloferax volcanii Strain Cured of Plasmid PHV2. Microbiol. Read. Engl. 2001, 147, 959-964. [CrossRef]

47. Hawkins, M.; Malla, S.; Blythe, M.J.; Nieduszynski, C.A.; Allers, T. Accelerated Growth in the Absence of DNA Replication Origins. Nature 2013, 503, 544-547. [CrossRef]

48. Delmas, S.; Shunburne, L.; Ngo, H.-P.; Allers, T. Mre11-Rad50 Promotes Rapid Repair of DNA Damage in the Polyploid Archaeon Haloferax volcanii by Restraining Homologous Recombination. PLoS Genet. 2009, 5, e1000552. [CrossRef]

49. Available online: https://sourceforge.net/projects/bbmap/ (accessed on 19 October 2020).

50. Becker, E.A.; Seitzer, P.M.; Tritt, A.; Larsen, D.; Krusor, M.; Yao, A.I.; Wu, D.; Madern, D.; Eisen, J.A.; Darling, A.E.; et al. Phylogenetically Driven Sequencing of Extremely Halophilic Archaea Reveals Strategies for Static and Dynamic Osmo-Response. PLoS Genet. 2014, 10, e1004784. [CrossRef]

51. Zdobnov, E.M.; Tegenfeldt, F.; Kuznetsov, D.; Waterhouse, R.M.; Simão, F.A.; Ioannidis, P.; Seppey, M.; Loetscher, A.; Kriventseva, E.V. OrthoDB v9.1: Cataloging Evolutionary and Functional Annotations for Animal, Fungal, Plant, Archaeal, Bacterial and Viral Orthologs. Nucleic Acids Res. 2017, 45, D744-D749. [CrossRef]

52. Kriventseva, E.V.; Kuznetsov, D.; Tegenfeldt, F.; Manni, M.; Dias, R.; Simão, F.A.; Zdobnov, E.M. OrthoDB V10: Sampling the Diversity of Animal, Plant, Fungal, Protist, Bacterial and Viral Genomes for Evolutionary and Functional Annotations of Orthologs. Nucleic Acids Res. 2019, 47, D807-D811. [CrossRef] [PubMed]

53. Oberto, J. SyntTax: A Web Server Linking Synteny to Prokaryotic Taxonomy. BMC Bioinform. 2013, 14, 4. [CrossRef] [PubMed]

54. Chen, I.-M.A.; Chu, K.; Palaniappan, K.; Pillay, M.; Ratner, A.; Huang, J.; Huntemann, M.; Varghese, N.; White, J.R.; Seshadri, R.; et al. IMG/M v.5.0: An Integrated Data Management and Comparative Analysis System for Microbial Genomes and Microbiomes. Nucleic Acids Res. 2019, 47, D666-D677. [CrossRef] [PubMed]

55. Mukherjee, S.; Stamatis, D.; Bertsch, J.; Ovchinnikova, G.; Katta, H.Y.; Mojica, A.; Chen, I.-M.A.; Kyrpides, N.C.; Reddy, T. Genomes OnLine Database (GOLD) v.7: Updates and New Features. Nucleic Acids Res. 2019, 47, D649-D659. [CrossRef] [PubMed]

56. Kelley, L.A.; Mezulis, S.; Yates, C.M.; Wass, M.N.; Sternberg, M.J.E. The Phyre2 Web Portal for Protein Modeling, Prediction and Analysis. Nat. Protoc. 2015, 10, 845-858. [CrossRef]

57. Galperin, M.Y.; Makarova, K.S.; Wolf, Y.I.; Koonin, E.V. Phyletic Distribution and Lineage-Specific Domain Architectures of Archaeal Two-Component Signal Transduction Systems. J. Bacteriol. 2018, 200, 1-16. [CrossRef] 
58. Ruepp, A.; Wanner, G.; Soppa, J. A 71-KDa Protein from Halobacterium salinarium Belongs to a Ubiquitous P-Loop ATPase Superfamily with Head-Rod-Tail Structure. Arch. Microbiol. 1998, 169, 1-9. [CrossRef]

59. Miranda, H.V.; Antelmann, H.; Hepowit, N.; Chavarria, N.E.; Krause, D.J.; Pritz, J.R.; Bäsell, K.; Becher, D.; Humbard, M.A.; Brocchieri, L.; et al. Archaeal Ubiquitin-like SAMP3 Is Isopeptide-Linked to Proteins via a UbaA-Dependent Mechanism. Mol. Cell. Proteom. 2014, 13, 220-239. [CrossRef]

60. Schulze, S.; Adams, Z.; Cerletti, M.; De Castro, R.; Ferreira-Cerca, S.; Fufezan, C.; Giménez, M.I.; Hippler, M.; Jevtic, Z.; Knüppel, R.; et al. The Archaeal Proteome Project Advances Knowledge about Archaeal Cell Biology through Comprehensive Proteomics. Nat. Commun. 2020, 11, 3145. [CrossRef]

61. Gropp, F.; Betlach, M.C. The Bat Gene of Halobacterium halobium Encodes a Trans-Acting Oxygen Inducibility Factor. Proc. Natl. Acad. Sci. USA 1994, 91, 5475-5479. [CrossRef]

62. Leong, D.; Boyer, H.; Betlach, M. Transcription of Genes Involved in Bacterio-Opsin Gene Expression in Mutants of a Halophilic Archaebacterium. J. Bacteriol. 1988, 170, 4910-4915. [CrossRef] [PubMed]

63. Laass, S.; Monzon, V.A.; Kliemt, J.; Hammelmann, M.; Pfeiffer, F.; Förstner, K.U.; Soppa, J. Characterization of the Transcriptome of Haloferax volcanii, Grown under Four Different Conditions, with Mixed RNA-Seq. PLoS ONE 2019, 14, e0215986. [CrossRef] [PubMed] 